\title{
EDUCAÇÃO ÉTNICO-RACIAL DE CRIANÇAS PEQUENAS NO "PERCURSO TERRITÓRIO NEGRO” DE MUSEUS EM BELO HORIZONTE ${ }^{1}$
}

Recebido em: 09/10/2021

Aprovado em: 05/11/2021

Licença: @) (1)

Andreza Mara da Fonseca

Vânia Noronha

Pontifícia Universidade Católica de Minas Gerais (PUC-Minas)

Belo Horizonte - MG - Brasil

RESUMO: Este artigo problematiza o fenômeno lazer na contemporaneidade e a urgência de adotarmos outros paradigmas para a análise de suas manifestações. Ele apresenta uma pesquisa realizada com crianças da Educação Infantil em museus no sentido de educar para outras sensibilidades. O estudo objetivou analisar as narrativas de crianças de 5 anos sobre a situação do povo negro no Brasil em nossa sociedade, possibilitada por visitas em dois museus de Belo Horizonte. Desse modo, a articulação dos conceitos de lazer, infância, currículo, educação e linguagem museal, permitiu análises que caminharam na direção de uma educação étnico-racial dessas crianças. A pesquisa qualitativa adotou o estudo de caso e as estratégias de análise documental, entrevistas, observação participante. Percebeu-se uma leitura positivada sobre o povo negro pelas crianças e a constituição de outros imaginários oportunizada por práticas lúdicas fora do contexto escolar.

PALAVRAS-CHAVE: Educação étnico-racial. Infância. Museus.

\section{EDUCATION OF YOUNG CHILDREN IN THE "BLACK TERRITORY ROUTE" OF BELO HORIZONTE'S MUSEUMS}

ABSTRACT: This paper discusses the phenomenon of leisure in contemporary times and the urgency of adopting other paradigms to analyze its manifestations. It presents a research carried out with children from kindergarten in museums in order to educate for other sensibilities. The study aimed to analyze the narratives made by 5 -year-old children about the situation of the black people in our society, powered by visits to two museums in the city of Belo Horizonte. Thereby, the articulation of the concepts of childhood, curriculum, education and museum language allowed analyses that moved towards an ethno-racial education for these children. The qualitative research adopted the case study and document analysis strategies, interviews, participant observation. Thus, we see a positive reading about black people by the children and the constitution of other imaginaries made possible by playful practices outside the school context.

\footnotetext{
${ }^{1}$ Esse artigo é uma versão revista e ampliada de uma comunicação apresentada no XI COPENE sob o título "Aqui não tem máscaras africanas? A educação étnico-racial em uma EMEI e a experiência com o Percurso Território Negro em museus de Belo Horizonte/MG” (FONSECA; NORONHA, 2020).
} 
KEYWORDS: Ethnic-racial education. Childhood. Museums.

\section{Introdução}

Este artigo se propõe a contribuir com o debate sobre o conceito de lazer ao se aproximar de problematizações contemporâneas sobre o esgotamento do paradigma clássico em nossas sociedades modernas e a necessidade urgente de uma nova reparadigmatização, tendo como foco a educação para as relações étnico-raciais. Nesse sentido, o artigo desenvolve inicialmente uma reflexão sobre uma possibilidade do lazer ser compreendido no paradigma emergente da complexidade tendo a antropologia do imaginário como aporte teórico. Em seguida, apresenta uma pesquisa como exemplo de ação educativa incipiente na direção dessa mudança paradigmática.

A pesquisa foi realizada com crianças da Educação Infantil de uma escola municipal de Belo Horizonte em museus da cidade, constituintes do Percurso Território Negro, que integra o Circuito de Museus contemplado pela Secretaria Municipal de Educação de Belo Horizonte (SMED/BH) e proporciona o contato com a história e memória de negros e negras em nossa sociedade ${ }^{2}$. A experiência de lazer e ludicidade oportunizada pelas escolas sugere reflexões sobre as condições do povo negro desde o período escravocrata até os dias de hoje, e desse modo, contribui para a educação étnico-racial das crianças de pouca idade.

Assim, nosso interesse com a pesquisa foi o de compreender a fala das crianças ao entrarem em contato com situações vividas por esses sujeitos em diferentes contextos proporcionados pela linguagem museal. A pesquisa qualitativa adotou o estudo de caso e as estratégias de análise documental, entrevistas, observação participante. O estudo aborda os conceitos de lazer, infância, currículo, educação e linguagem museal;

\footnotetext{
${ }^{2}$ A pesquisa empírica aqui apresentada é fruto da dissertação de mestrado de Andreza Mara Fonseca intitulada: "Aqui não tem máscaras africanas?" A educação étnico-racial em uma EMEI e a experiência com o percurso território negro em museus de Belo Horizonte/MG, 2019.
} 
apresenta as ações metodológicas para o desenvolvimento das visitas aos museus e as observações no momento das visitas. Nas considerações finais o artigo conclui que essas práticas lúdicas, fora do contexto escolar, permitiram uma leitura positivada sobre o povo negro pelas crianças, com a constituição de outros imaginários e abordagem de outros referenciais teóricos pelas autoras ao trabalharem essa discussão.

\section{Ampliando o Olhar sobre o Fenômeno Lazer}

O lazer, tal qual conhecemos e vivenciamos na atualidade, tem sido considerado um fenômeno moderno atrelado aos modos de produção capitalista, reconhecidamente constituinte do que alguns autores têm denominado binômio trabalho/lazer (GOMES, 2019). Nessa perspectiva conceitual, o tempo livre do trabalhador para usufruir de outras experiências na vida é considerado uma extensão do trabalho. Desse modo, no tempo do descanso do trabalho e das demais obrigações cotidianas, o trabalhador fica preso à mesma lógica do sistema produtivo. Também podemos conceber o lazer numa perspectiva subjetiva e ainda como uma dimensão da cultura (GOMES, 2019).

Dialogando com Castro-Gómez (2005), podemos afirmar que o lazer moderno, particularmente em sua gênese, atendeu aos interesses da sociedade capitalista gerando a necessidade de disciplinarização para o trabalho, em que o tempo e o corpo do trabalhador se tornaram subordinados ao labor.

Ao longo da história da educação brasileira podemos notar que também as crianças foram (e continuam sendo) educadas com vistas à disciplinarização e docilização dos seus corpos, numa concepção propedêutica que pensa esses sujeitos como os futuros trabalhadores da nação. Desde cedo elas são inseridas num contexto escolar que reforça dicotomias; privilegia o intelecto em detrimento das emoções; fragmenta o conhecimento em disciplinas e atribui status diferenciados, estabelecendo hierarquias dos saberes; prepara para o trabalho e condiciona a experiência do lazer a 
Educação Étnico-racial de Crianças Pequenas no "Percurso Territorio Negro"...

Andreza Mara da Fonseca e Vânia Noronha

pequenos intervalos entre as aulas, os recreios, ou a episódios nas áreas de conhecimento. Assim, elas se apropriam sutilmente de valores presentes na sociedade capitalista, inclusive no que diz respeito ao trabalho e ao lazer, em seu processo de formação escolarizada. Com base nessas colocações, é possível afirmar que a formação para o trabalho a dimensão privilegiada nos processos educativos.

Poucas são as disciplinas que desenvolvem na escola o desejo desses sujeitos de aprender e saborear as práticas culturais lúdicas existentes em nossa realidade, com vistas a uma educação que se volte para a formação de pessoas que compreendam o significado do lazer em suas vidas. Por vezes, mesmo disciplinas como a Educação Física e a Arte, trabalham seus conteúdos num viés racionalista e reprodutivista, que mais favorecem a apropriação de conteúdos disseminados pela indústria cultural, com pouca margem para a resistência a ela. Mas felizmente existem as exceções, nas quais práticas criativas ganham relevância, como a que será aqui apresentada.

Numa vertente capitalista, o lazer se torna a face privilegiada da indústria cultural (VAZ, 2006), que, por meio de seus veículos e estratégias, seduzem o estudante/ trabalhador ao consumo. As mídias, principalmente as de comunicação e informação, cada vez mais antenadas e sofisticadas, exercem poder sobre os indivíduos, em faixas etárias cada vez mais novas, que acatam inconscientemente os mandos dessa indústria, ainda que não sejamos neutros a ela. As tecnologias digitais contemporâneas vendem a ideia de que por meio de muitos e diferentes aplicativos vão facilitar as nossas vidas e com isso aumentar o nosso tempo livre para outras experiências. Entretanto, o tempo que deixamos de consumir com deslocamentos para compras, serviços bancários, dentre outros, não se concretiza como mais tempo para o lazer. Ao contrário, as mudanças possibilitadas nessa relação com tempos e espaços tem favorecido muito mais ao capital do que ao próprio sujeito. Estamos cada dia mais viciados nessas tecnologias 
e distantes de nossa própria subjetividade, desejos e interesses. De tal modo que muitas pesquisas no campo do lazer já destacam os efeitos desse processo na vida dos sujeitos, inclusive em adolescentes (SILVEIRA, 2019).

Vivemos numa sociedade capitalista e, por isso mesmo, não é o caso de defendermos que essa concepção de lazer esteja equivocada. Mesmo nós, pesquisadores do campo, por vezes, nos vemos fazendo escolhas por práticas lúdicas completamente atreladas à mercadorização dos produtos do lazer, numa nítida relação com a reprodução social e cultural, as desigualdades, os modismos, o consumo e o lucro. Entender isso nos permite compreender a ambiguidade desse fenômeno, que pode acatar os ditames da sociedade capitalista ao mesmo tempo em que encontra na sua própria estrutura as possibilidades de realizar críticas e transformá-la.

Essa constatação nos coloca diante da urgência de pensarmos processos educativos em todos os segmentos de ensino que considerem o lazer e sua potência para a ampliação da leitura de mundo dos sujeitos e que esses se tornem autônomos para fazer escolhas, tomar decisões, assumir um posicionamento crítico perante as práticas lúdicas a eles ofertadas. Processos educativos que favoreçam a construção de vínculos afetivos e solidários entre as pessoas em prol da vida coletiva digna, do respeito às culturas e de um planeta sustentável para todos. Processos educativos que reconheçam o lazer como direito de todos, todas e todes, desde a infância até a velhice, garantido em documentos constitucionais e outros normativos, mas não do mesmo modo, pelas ações das políticas públicas.

O lazer precisa ser entendido como uma dimensão da vida humana tão importante quanto todas as outras. Lazer é cultura, é saúde, é educação, são políticas públicas, é luta, é resistência, é relação com os modos de ocupação das cidades, da natureza e do meio ambiente. Todavia, antes de tudo, o lazer é imaginário. Para Durand 
(2002, p. 18) o imaginário (imaginação) "é o conjunto das imagens e relações de imagens que constitui o capital pensado do Homo sapiens - aparece-nos como o grande denominador fundamental, onde se vêm encontrar todas as criações do pensamento humano." O imaginário nos remete a uma esfera psíquica na qual imagens adquirem forma e sentido devido sua natureza simbólica. Ele está em todas as ações humanas, mas, certamente, encontra nas manifestações de lazer uma abundância de imagens que constituem nosso imaginário individual, pois está enraizado em nossa bio-história pessoal, que, ao mesmo tempo, se apoia no imaginário coletivo. Este último constitui uma gramática simbólica de imagens primordiais e arquetípicas da espécie humana. A imaginação, para Durand (2002), é o dinamismo organizador que permite aos humanos enfrentar a angústia existencial do tempo que passa e da morte que se aproxima.

Assim entendido, do mesmo modo que o trabalho, o lazer é condição de sobrevivência, de nosso estar no mundo, de "se permitir" viver com alegria e disposição, de preencher os vazios, de nos trazer a vontade para enfrentar os problemas cotidianos, com liberdade e desejo de criar e recriar constantemente a própria vida. É produção simbólica, condição de nossa humanidade, campo aberto às experiências, ao possível. Pensar o lazer dessa maneira nos exige outra perspectiva paradigmática.

Morin é um dos autores que vem nos provocando a pensar no contexto da contemporaneidade e nas mudanças, que já estão em curso, na direção desse outro paradigma, ao qual ele denomina emergente ou da complexidade Em uma entrevista cedida para o programa Roda Viva, na TV Cultura, em 2000, ele foi indagado sobre o lazer e a presença de outras práticas culturais para a sua formação, além das cognitivas e racionais. Ele narra como essas lhe marcaram, comoveram e revelaram verdades que estavam no seu inconsciente, permitiram que fizesse suas escolhas e se tornasse o intelectual que ainda o é. Nesse contexto, ele destaca sua aproximação com a literatura, 
a pintura e as possibilidades de questionar sobre o universo, a cultura, a ciência, o homem, a vida e a morte. Sobre o lazer, disse ele naquele momento:

Agora, esta questão do lazer...é muito importante porque nas sociedades tradicionais a alternância é o cotidiano e, depois, a festa. Nas sociedades arcaicas, a festa é um grande momento de transgressão, gastos, jogos e delírios. Então, em nossas sociedades modernas acreditou-se em fazer uma separação. O trabalho depois o lazer. Ora, o lazer é a possibilidade da festa, não é? Felizmente! Mas é um espaço vazio. (...) O lazer, portanto, é uma possibilidade de cultura. O que falta é o incentivo para desenvolver tal cultura. $\mathrm{O}$ que falta talvez sejam universidades permanentes em que qualquer um possa lecionar, hoje o que irá se desenvolver é a TV cultural, e isto é o tipo de coisa útil. Mas por outro lado, percebemos a necessidade da festa, em nossa civilização (...) Há uma necessidade de festa, de vida, de poesia de vida. (...) Acho que também é um esforço permanente para oferecer cultura. Ela não pode ser imposta. Não devemos impô-la, mas oferecer possibilidades. Oferecer as possibilidades à juventude (...) Tantas crianças com tantas possiblidades, tão ricas e não podemos explorá-las. São jogadas no trabalho, no cotidiano e na burocracia. $\mathrm{O}$ verdadeiro problema é este. $\mathrm{E}$ atualmente o quanto o lazer tem de se expandir, já que cabe às máquinas os trabalhos pesados e, inclusive, o controle! Hoje esse espaço não deve mais ser chamado de lazer, mas sim o espaço da vida vivida (MORIN, 2000a).

Há 21 anos, Morin já nos apontava importantes reflexões e desafios não só para o lazer, mas também para a necessidade da mudança paradigmática. A contemporaneidade, esse estágio da globalização que estamos vivendo, tem trazido muitos outros desafios. O mundo confuso e em crise, principalmente, nesses tempos pandêmicos, tem nos mostrado que a cultura, a arte, a poesia, a literatura, a música, nunca foram tão imprescindíveis. Nesse contexto, uma educação que considere a dimensão sensível dos humanos, a alma, os sonhos, o imaginário, os mitos, os símbolos, as emoções, se faz ainda mais urgente. A vida não está dada, não estamos prontos, constatação que nos tem feito questionar sobre a nossa própria humanidade (KRENAK, 2019).

Autores como Santos (2002) e o próprio Morin (2000b) vêm afirmando que não se trata de substituir o paradigma clássico por outro, mas, certamente, de construir novos referenciais, o que é cada vez mais necessário. Nesse sentido, a cultura, por exemplo, num paradigma emergente, deixa de ser a ordem e passa a ser a desordem, o caos. Os sujeitos não são os mesmos, não têm as mesmas demandas. A globalização 
promoveu a diferença, a pluralidade, a diversidade, a estilização da vida. A cultura se torna aquilo que é experienciado no cotidiano, numa profusão de estilos de vida e paisagens (CANEVACCI, 1993; CANCLINI, 1997). Espera-se dos sujeitos não mais o pensar com a razão, e sim, o agir com emoção.

Esse paradigma emergente se baseia numa razão aberta, pretendendo uma visão complexa e global da sociedade. Nele a cultura passa a ser entendida, como nos diz Morin (2000b), enquanto um universo das mediações simbólicas que organiza os grupos sociais, considerando o circuito metabólico entre dois polos: o das formas estruturantes, o instituído (as organizações, instituições, códigos, formações discursivas, sistemas de ações) e o do plasma existencial, o instituinte (os grupos sociais, suas vivências, espaços, afetividades). Nesse modelo considera-se o plural, o diferente, o conflitual que se fazem presentes no interior dos grupos sociais, nas relações e interações dos sujeitos com o mundo.

Nesse paradigma, também o conceito de humano precisa ser ampliado. Morin (2000b) afirma que o homem não é apenas biológico ou cultural, e sim, totalmente biológico e cultural. O Homo sapiens é também demens (e aqui o autor inclui o Homo ludens). O sapiens contém o demens e nele está contido. Essa bipolaridade existencial constitui nossas duas vidas: uma séria, utilitária, prosaica; a outra lúdica, estética, poética. Para Morin (2000b), uma vida totalmente racional, técnica e utilitária seria não apenas demente, mas inconcebível. Do mesmo modo, uma vida sem nenhuma racionalidade seria impossível. O homem vive a alternância entre prosa e poesia. Para ele, a privação da poesia é tão fatal quanto a do pão.

Entendido desse modo, o ser humano se torna um ser aberto para o mundo, um especialista da não especialização, um aprendiz por curiosidade ativa, um lúdico explorador, permanentemente incompleto, inacabado, ambíguo, ambivalente e crísico, 
um ser de perigo, da aléa, do risco, da desordem complexificante. Um ser humano que se articula com o ludismo da cultura, como campo exploratório para a criatividade e se abre ao campo do possível, na vida imaginária, no trabalho científico criativo, na poiésis (PAULA CARVALHO, 1990), e nós acrescentaríamos, no lazer e na festa (NORONHA, 2017).

O lazer, o jogo, a festa, o rito e o entretenimento, nesse paradigma, não são apenas distrações, divertimentos com vistas a recuperar as forças físicas do trabalhador, possibilidade de recarregar as baterias e contribuir para minimizar as mazelas sociais. Estes seriam fenômenos constituintes de uma dimensão imprescindível na formação humana, uma educação das sensibilidades, que, como nos diz Morin (2000b), tem raízes que mergulham nas profundezas humanas do psiquismo e da afetividade: a magia, o imaginário, o mito, a religião, a despesa, o desperdício, a estética, a poesia.

Ao reconhecer a necessidade da mudança paradigmática aqui tratada, cabe a escola compreender o seu papel numa educação outra que considere esse novo paradigma, educando crianças, adolescentes e jovens para experiências racionais e sensíveis que abram espaços para a descoberta, a emoção, a fantasia, o devaneio, o sonho. Uma educação das sensibilidades que envolva todas as áreas do conhecimento e suas contribuições para o desenvolvimento da imaginação, e não, da cristalização de certezas disjuntoras, como quer o paradigma clássico. Nessa vertente teórica, vários são os autores que defendem o imaginário como esse "sem-fundo humano, que é a criação" (RUIZ, 2003, p. 24).

Assim, cabe a escola favorecer o desenvolvimento da imaginação no sujeito imaginante, explorando o vasto museu imaginário presente na ontologia humana, com seus símbolos, arquétipos, ritos e mitos. Duborgel (1992) defende que as escolas coloquem a disposição dos educandos, em todas as fases da sua formação, mostras do 
museu imaginário sob todas as suas formas e linguagens, como objetos, lendas, mitos, imagens, contos, poemas, dentre outras, para o deleite e o consumo, a meditação, o devaneio e a produção criativa, com vistas a desenvolver uma Pedagogia do Imaginário.

Defendemos que essa pedagogia do imaginário encontre brechas nos currículos fechados e normativos de nossas escolas tanto no trato com os diferentes conhecimentos quanto na exploração dos espaços da própria instituição ou outros equipamentos disponíveis no entorno dela e/ou na cidade. Assim, entendemos que a escola pode e deve educar também para as experiências de lazer, de ócio, de fruição e de imaginação, sendo a ludicidade a expressão das sensações por elas propiciadas, vivenciadas, afetadas. Desse modo, segundo Saura (2014),

o lazer atua, ou pode atuar - se não reduzido a atitudes recreacionistas e pedagogizantes - a partir dessa fonte imaginal, manifesta no lúdico. Assim, os poderosos 'momentos de lazer' falam ou melhor, movimentam algo profundo e regenerador de nossa natureza. (...) Nas crianças, em seus momentos de lazer e brincar espontâneo, o repertório imaginal humano manifesta-se de forma premente (SAURA, 2014, p.167).

Esse debate, certamente, se abre para outros escritos, estudos e pesquisas e demandam outros referenciais epistemológicos e metodológicos, que, por motivo de limitações de espaços, não faremos nesse momento. Com a intenção de caminhar nessa direção, apresentaremos nesse artigo, uma importante experiência para contribuir com as reflexões propostas até aqui. Temos ciência do que nos dizem Santos e Morin em relação à substituição de um paradigma por outro, mas, certamente, pesquisas desenvolvidas sobre a diversidade dos sujeitos, como a que aqui relataremos, podem ser consideradas passos incipientes para a sua efetivação.

Nesse contexto, este trabalho é fruto de uma pesquisa de mestrado (FONSECA, 2019) que privilegiou a escuta da fala de crianças sobre as relações étnico-raciais estabelecidas no diálogo entre uma proposta curricular e equipamentos de lazer (PELEGRINI, 2004), especificamente os museus de Belo Horizonte, que desenvolvem 
uma reflexão acerca da presença do negro no Brasil, por meio do Percurso Território Negro. Para tanto, inicialmente, discutiremos sobre as concepções de infância, educação étnico-racial e a linguagem museal, concepções estas que subsidiaram a pesquisa. Em seguida, apresentaremos o locus da pesquisa, suas problematizações e metodologia. Abordaremos ainda, as análises dos resultados alcançados articulando diferentes experiências culturais e aprendizados oferecidos por meio de práticas educativas lúdicas com vistas à educação das relações étnico-raciais, envolvendo equipamentos de lazer, como os museus.

\section{Conceituando Infância, Educação Étnico-Racial e Linguagem Museal}

Ao elencar a tríade infância, educação das relações étnico-raciais e linguagem museal (aquela que se estabelece num equipamento específico de lazer), como objetos de investigação, coloca-se em pauta a discussão sobre a temática racial e suas aproximações com outros contextos educativos, com base na escuta do que diz a criança. Currículo, infância e museus, encadeados, fazem emergir a inquietação inicial sobre quais narrativas são elaboradas pelas crianças sobre as relações étnico-raciais ao visitar o Percurso Território Negro, na cidade de Belo Horizonte. O que dizem as crianças quando realizam visitas a esses equipamentos de lazer possibilitadas pela proposta curricular de uma Escola Municipal de Educação Infantil de Belo Horizonte, tendo como mediação a educação e a linguagem museal?

Ao realizar o levantamento bibliográfico sobre a temática, identificamos uma lacuna em pesquisas que articulam infância, museu e educação étnico-racial, e que tenham como proposta ouvir o que as crianças têm a dizer sobre a temática. Por isso, consideramos a urgência e a emergência de contribuições propiciadas por trabalhos que explorem diferentes equipamentos de lazer disponíveis em nossas cidades, ampliando a curiosidade das crianças e suas descobertas, no sentido de possibilitar uma educação 
voltada para a valorização da diversidade étnico-racial, o reconhecimento das diferenças e o respeito aos sujeitos.

O referencial teórico que sustentou essa pesquisa propõe um diálogo e o cruzamento entre as teorias da educação na perspectiva do direito, do currículo, das relações étnico-raciais, da infância, do lúdico e da educação museal. Para entender a educação como princípio, direito social e de cidadania dos brasileiros, presume-se que todos os indivíduos são sujeitos, devendo suas histórias, culturas e ancestrais serem estudados de maneira positiva, sem hierarquização ou subalternização. A efetivação da educação como um dos direitos fundamentais de cada sujeito, seja ele criança, jovem ou adulto, é o que qualifica o Estado Democrático de Direito.

A educação e o lazer estão garantidos na Constituição Brasileira de 1988 como direito social ${ }^{3}$, que inclui a diferença e a diversidade. Segundo Cury (2007), a “Constituição da República e a Lei de Diretrizes e Bases da Educação Nacional conferem uma relevância à educação ao elevá-la à categoria de princípio e de direito, articulando-a com a proteção e a dignidade da pessoa humana" (CURY, 2007, p. 1). O lazer também se faz presente em diferentes artigos no Estatuto da Criança e do Adolescente (ECA).

Em uma perspectiva histórica, desde a invasão dos portugueses em nosso país e o estabelecimento do processo escravocrata, podemos destacar importantes estratégias que o povo negro adotou tendo expressões culturais como mote para a luta e resistência. Vale destacar a presença da capoeira, do samba, do jongo, do congado, do maracatu, e tantas outras manifestações que constituíram (e constituem) a subjetividade e as

\footnotetext{
${ }^{3}$ Os Direitos Sociais são uma grande conquista dos trabalhadores no século XX, que, embora tenham repercutido com mais notoriedade em tal momento, fazem parte de um processo de longo prazo e que exige alto investimento. Para proporcionar uma vida digna ao cidadão ou, como diz T. H. Marshall, permitir que ele tenha uma vida de ser civilizado, o Estado deve garantir o direito à vida, o direito à igualdade, o direito à educação, o direito de imigração e emigração e o direito de associação. A atual Constituição Brasileira, de 1988, por exemplo, estabelece que são Direitos Sociais o acesso à educação, saúde, alimentação, trabalho, moradia, lazer, segurança, e a proteção à maternidade, à infância e aos desamparados (CURY, 2002).
} 
identidades do nosso povo. O percurso traçado muito antes da Constituição de 1988 até a normatização decorrente da aprovação de algumas leis, que consideram a realidade de diferentes grupos sociais (como é o caso da Lei 10.639/03 sobre a obrigatoriedade do ensino da história da África e da Lei 11.645/08, que prevê o ensino sobre os indígenas, dentre outras), revela a luta de diversos atores em nosso país, lidando com diferentes estratégias, inclusive lúdicas, como o teatro negro, jornal específico, a frente de luta popular, a criação de um partido político, dentre tantas outras (GOMES, 2017). Mas, ainda que todo esse processo de luta persista em existir no país, não conseguimos erradicar os males provocados pela escravização das pessoas negras e o combate ao racismo é uma realidade. É inegável a responsabilidade da escola e das práticas de lazer na construção dessa luta.

Santos (2009) afirma que, na educação, leis como a 10.639/03 tem como objetivo reposicionar o negro e as relações raciais no mundo da educação, o que requer inserir conteúdos, rever práticas e posturas pedagógicas, materiais e métodos pedagógicos, conceitos e paradigmas. Além disso, esta lei almeja transformar a forma como as escolas desenvolvam práticas de educação das relações raciais no seu cotidiano (marcado pela reprodução da discriminação e pelo silenciamento diante do racismo), e transversalizar a discussão pelas diferentes disciplinas. Enfim, uma pauta bastante robusta, diversa e complexa que se insere diretamente nos jogos de poder em todos os âmbitos de construção e regulação das práticas sociais, que são também educativas.

Conhecer, reconhecer, valorizar a diversidade e respeitar as sociodiversidades e identidades múltiplas exige que a sociedade repense valores fundamentais. Neste contexto, toda a população brasileira, incluindo as crianças, carece de um outro olhar social, não hegemônico, e decolonial, de modo a alcançar também a produção de conhecimentos e reinventar as relações sociais e epistemológicas, como propôs Santos 
(2004), para quem devemos:

Aprender com o Sul - entendendo o Sul como uma metáfora do sofrimento humano causado pelo capitalismo - significava precisamente o objetivo de reinventar a emancipação social, indo mais além da crítica produzida no Norte e da práxis social que ela subscrevera (SANTOS, 2004, p. 6).

Nessa perspectiva de reinvenção das relações, a infância deve ocupar lugar de destaque, possibilitando a vivência plena da cidadania desses sujeitos. Pensar na infância remete inevitavelmente às concepções modernas que definem os sujeitos dessa faixa etária como pertencentes a uma categoria social. Essas concepções são discutidas por estudiosos contemporâneos que se apoiam na Sociologia da Educação, como Corsaro (2011), Sarmento (2005), Quinteiro (2002), Reis (2009), e no lazer, como Gomes e Isayama (2008), entre outros.

Esses autores buscam entender a realidade da sociedade com base na análise de possibilidades de vivência da infância, relacionadas às classes sociais, ao tempo e espaço em que são geradas, além de suas conexões com as contínuas e diversas transformações sociais, culturais, econômicas e políticas. Essa análise permite entender a importância da contextualização dessa infância e suas relações sociais em diversos aspectos, espaços e tempos.

No campo do lazer, as pesquisas consideram que existem diferentes infâncias na realidade brasileira, uma vez que somos um país diverso e com realidades socioeconômicas, religiosas, étnicas, capacitistas, dentre outras, diferentes. As crianças são sujeitos de direitos, singulares e plurais. O Estatuto da Criança e do Adolescente (ECA, Lei n.8.069, de 13 de julho de 1990), em seu artigo $4^{\circ}$ considera que:

É dever da família, da comunidade, da sociedade em geral e do poder público, assegurar, com absoluta prioridade, a efetivação dos direitos referentes à vida, à saúde, à alimentação, à educação, ao esporte, ao lazer, à profissionalização, à cultura, à dignidade, ao respeito, à liberdade e à convivência familiar e comunitária (BRASIL, 1990). 
Sendo um direito também das crianças, o poder público precisa, além de garantir o lazer, entender que a condição da criança como sujeito no mundo seja respeitada. Gomes e Isayama (2008) afirmam que analisar o lazer na infância é algo complexo e por vezes polêmico. Para eles, alguns teóricos consideram inadequado falar em lazer para o período da infância quando esse é analisado sobre o viés do binômio trabalho/lazer, já que, para a criança, a divisão das atividades obrigatórias das não obrigatórias ainda não é tão definida. Por isso, os autores sugerem que as reflexões não sejam atreladas a essa análise, e sim, que pensemos nas crianças como sujeitos de direitos, de viverem a sua cultura no aqui e agora, do privilégio de estarem no mundo e usufruírem das atividades lúdicas, principalmente o brincar. Vale lembrar que os documentos normativos para a Educação Infantil, apesar de não fazerem articulações com o lazer e o ócio, também destacam o brincar como fundamental na formação das crianças (BRASIL, 1998; BRASIL, 2018).

O olhar para a infância, contextualizada no tempo e espaço, exige de os todos atores sociais que esta seja considerada seriamente como uma etapa da vida essencial para afirmar a própria presença da criança no mundo. A esse respeito, Sarmento (2005) afirma que "as crianças são competentes e têm capacidade de formularem interpretações da sociedade, dos outros e de si próprios" (SARMENTO, 2005, p. 21). Certamente, as experiências vivenciadas nos tempos e espaços do lazer, nas praças, nas ruas, nos clubes, e demais equipamentos, contribuem para as descobertas de si, das relações com o outro, do fluir do imaginário e, principalmente, da condição de ser criança.

Nesse contexto, a escola ocupa um lugar privilegiado desde que considere também essas dimensões em suas propostas curriculares e na ocupação dos tempos e espaços escolares. Para isso, a Educação Infantil e seus processos educativos precisam estar alicerçados nas ações indissociáveis de cuidar e educar, compreendendo o direito à 
educação e ao lazer como princípios da formação da pessoa em sua essência humana e explorando todas as linguagens possíveis.

A brincadeira, expressão do lúdico por excelência para esses sujeitos, é o lugar do respeito e do reconhecimento da diversidade, da participação social, de forma crítica, ciente e consciente de seus direitos e deveres civis, sociais, políticos, econômicos e éticos. Infelizmente, não é o que estamos presenciando nas escolas atualmente (mesmo antes da pandemia). O lugar da brincadeira na escola tem sido o da premiação, quando as crianças "se comportam" bem em sala de aula, ou o da punição, quando ocorre o contrário. As áreas para a brincadeira na escola são escassas e os tempos para essa atividade cada vez mais encurtados.

É nítida a preocupação com a formação para a leitura e escrita em detrimento da escuta dos corpos e sua necessidade de movimento, interação, contatos, pulos, risos e alegria. Chegamos ao absurdo de estar sendo pensada a adoção de livros didáticos para esses sujeitos. Definitivamente a imaginação não tem tido lugar nesse processo formativo.

Defendemos que os processos educativos na infância reconheçam a importância da busca por um currículo amplo, inclusivo, lúdico e crítico em uma perspectiva decolonizadora, que considere os diferentes grupos étnico-raciais e suas diversidades culturais. O projeto de currículo e sociedade decolonial está assentado nas lutas dos movimentos sociais, teóricos e pesquisadores por direitos, visibilidade e respeito à ancestralidade, bem como aos modos de ser e viver, contra os padrões de poder hegemônicos, excludentes, silenciadores e hierarquizantes.

Os conhecimentos eleitos para serem transmitidos pela escola compõem o currículo e, por consequência, as práticas pedagógicas. O currículo é uma das 
dimensões em que se materializam as relações de poder e as disputas na escola e carrega diversas “conexões entre linguagem e poder" (MOREIRA, 1995, p. 11).

Práticas sistemáticas de discriminação são propagadas pelas mídias, meios de comunicação e também pela escola, que materializa no currículo ações individuais, institucionais e estruturais que circulam na sociedade. Este círculo estrutural, baseado em padrões coloniais de poder, excludentes e discriminatórios, precisa ser repensado, principalmente pela escola, para que, também por meio do currículo, possa contribuir para a construção de "medidas que coíbam o racismo individual e institucional" e reflita sobre as necessárias e profundas "mudanças nas relações sociais, políticas e econômicas" (ALMEIDA, 2018, p. 39).

Para Sodré (2012, p. 185), a força motriz da diversidade cultural está em "autossensibilizar-se de maneira a tomar contato com a gênese contingente de suas crenças, valores e atitudes". Acreditamos que seja esta a intencionalidade do Circuito dos Museus de Belo Horizonte ao constituírem o Percurso Território Negro e provocar novas possibilidades de construções do conhecimento das crianças de escolas do município. Tal como diz Gomes (2012), essa prática é reinventar os olhares, as relações, as trajetórias dos sujeitos diversos por meio de práticas inclusivas.

$\mathrm{Na}$ perspectiva de um currículo decolonial, que atenda o disposto nas Leis $10.639 / 2003$ e $11.645 / 2008$, e ainda mais integrado com o potencial cultural da cidade e do conceito educativo, é preciso investir, também, em processos não escolarizados para a educação das relações étnico-raciais. Nesse sentido, instigar as crianças a observar a presença de negros(as) e indígenas em diferentes espaços e equipamentos de lazer podem contribuir para que elas mesmas analisem e construam referências sobre essas realidades. Todos os contextos e ambientes em que a criança circula são potenciais para a reflexão, fruição de identidades e experiências lúdicas. 
As preocupações crescentes em torno da produção das identidades por meio do estímulo à valorização e preservação da memória social e coletiva, a frequência a esses espaços se configura como um gesto de pertencimento. Torna-se também uma aposta na possibilidade de construção de novas práticas de cidadania, por meio da promoção do acesso aos bens culturais e patrimoniais (DUTRA, 2003).

Os museus revelam-se, desse modo, como equipamentos de educação e investigações originais, capazes de anunciar a possibilidade de um diálogo amplo sustentado em pressupostos pautados na diversidade e na ludicidade. As visitas aos museus identificados para este estudo (Museu de Artes e Ofícios, Espaço UFMG do Conhecimento) reconhecem o potencial dos equipamentos de lazer existentes na cidade de Belo Horizonte e as múltiplas experiências lúdicas neles contidas. A escolha por esses equipamentos se deu pelo fato de possuírem itinerários temáticos que atendem à proposta curricular da escola pesquisada e ao recorte das discussões étnico-raciais de valorização da cultura afro-brasileira, por meio do Percurso Território Negro e do trabalho desenvolvido por seus setores educativos, na perspectiva de uma educação museal lúdica.

\section{O Locus da Pesquisa, Problematizações e Metodologia}

O Percurso Território Negro visa incentivar e facilitar a ocupação dos espaços museais pelo público escolar, de modo a possibilitar a apropriação de conhecimentos acerca das culturas africana e afro-brasileira, de suas histórias, produções intelectuais, científicas, tecnológicas e estéticas, além de suas formas de organização social. Esperase que, com essa ação, seja despertado nos sujeitos (mesmo nos de pouca idade) a curiosidade para visitar outros equipamentos de mesma natureza, contribuindo para a constituição do seu museu imaginante, como discutido anteriormente. Para participar, a 
escola interessada inscreve um projeto relacionado a uma das temáticas do Circuito e, caso selecionada, tem agendadas as visitas ao Percurso.

No que diz respeito à infância, a articulação escola/museu surgiu por meio do projeto "Educando a Cidade para educar na Educação Infantil", uma das ações da Gerência de Coordenação da Educação Infantil (GECEDI/SMED) que tem por objetivo garantir a inserção das crianças de 0 a 6 anos de idade nos espaços culturais da cidade e potencializar as interações mediadas por esses espaços. O Percurso Território Negro possibilita ainda atividades pedagógicas interdisciplinares de educação e lazer, tendo como ponto de partida a memória social e coletiva do Brasil, país multicultural e pluriétnico e trazendo como finalidade apresentar Belo Horizonte, destacando na paisagem as marcas valorativas da ancestralidade negra, em espaços de lazer e cultura.

Os museus parceiros acolheram a ideia da SMED/PBH de construir um percurso narrativo, consolidando o pensamento que tem orientado pesquisadores da área museológica que, por meio de ferramentas educativas, ressaltam iniciativas para a configuração de um espaço de diálogo, reflexão, acessibilidade, pertencimento e apropriação. Os museus participantes do Percurso Território Negro se inseriram de maneira efetiva neste diálogo do patrimônio com a infância, promovendo discussões e estudos, movimentando seus setores educativos para a reestruturação da mediação com foco nas crianças, incluindo atividades lúdicas e interativas voltadas para este público.

Compõem o Percurso Território Negro para a infância os museus: Memorial Minas Gerais Vale, Museu de Artes e Ofícios, Museu Brasileiro do Futebol e Espaço UFMG do Conhecimento, por possuírem itinerários temáticos que suscitam discussões sobre a educação étnico-racial e valorização da cultura afro-brasileira. A pesquisa foi realizada no Museu de Artes e Ofícios (MAO) e no Espaço do Conhecimento/UFMG 
(EC/UFMG). As informações sobre a criação e acervo do Museu de Artes e Ofícios

(MAO) são encontradas em seu ambiente virtual, conforme se pode ver a seguir:

O Museu de Artes e Ofícios - MAO é um espaço cultural que abriga e difunde um acervo representativo do universo do trabalho, das artes e dos ofícios no Brasil. Um lugar de encontro do trabalhador consigo mesmo, com sua história e com seu tempo. Criado a partir da doação ao patrimônio público de mais de duas mil peças entre objetos, instrumentos e utensílios de trabalho do período pré-industrial brasileiro, o Museu revela a riqueza da produção popular, os fazeres, os ofícios e as artes que deram origem a algumas das profissões contemporâneas (MUSEU DE ARTES E OFÍCIOS, 2021).

Segundo a referência do site, para abrigar o museu foram restaurados dois prédios antigos tombados pelo patrimônio público e aberto à população em 2006. O MAO está localizado na Estação Ferroviária Central de Belo Horizonte, ao lado da Estação Central do Metrô e a gestão do equipamento é de responsabilidade, desde julho de 2016, do Serviço Social da Indústria (SESI) MG, entidade do Sistema da Federação da Indústria do Estado de Minas Gerais (FIEMG).

Já o Espaço do Conhecimento/UFMG (EC/UFMG) é um espaço cultural que conjuga cultura, ciência e arte numa parceria entre o governo do Estado de Minas Gerais e a Universidade Federal de Minas Gerais (UFMG). Desde 2017, o Espaço, localizado na Praça da Liberdade, recebe o patrocínio da Unimed-BH pela Lei Federal de Incentivo à Cultura. Está. E em seu site ele apresenta suas ações e missão:

O Espaço do Conhecimento UFMG é um espaço cultural diferenciado, que conjuga cultura, ciência e arte simultaneamente. Sua missão não se limita à difusão do conhecimento científico, mas também à produção de diversos saberes, trabalhando no sentido de propor linguagens que combinam, inovam e fruem conteúdos, de forma lúdica (EC/UFMG, 2019).

A pesquisa aqui em destaque privilegiou análises sobre as estratégias curriculares mobilizadoras para a realização das visitas das crianças aos museus, com a identificação dessas estratégias, observando-se como são exploradas pelo currículo. Com base nessas problematizações, o objetivo da proposta de pesquisa foi investigar as narrativas das crianças sobre as relações étnico-raciais, dos negros em particular, para 
compreender como são desenvolvidas pelo currículo de uma Escola Municipal de Educação Infantil (EMEI) de Belo Horizonte, tendo como mediação a educação e a linguagem museal. Em outras palavras, interessava perceber como estas relações são tratadas pelo currículo da Educação Infantil antes, durante e depois das visitas ao Percurso Território Negro pertencente ao Circuito de Museus.

Para alcançar esse objetivo, este trabalho adotou a abordagem qualitativa e a estratégia do estudo de caso. Centrou-se na análise da temática sobre as relações étnicoraciais, tendo como foco as crianças de uma turma do segundo ciclo da Educação Infantil de uma escola municipal (EMEI) da Região Oeste de Belo Horizonte e suas narrativas, após visitas aos museus. A turma era composta por 25 crianças de 05 a 06 anos, do turno da manhã. Foram 18 os sujeitos da pesquisa sendo 8 meninos e 10 meninas, e as 2 professoras responsáveis pela turma. As crianças eram, em sua maioria, negras, representativas do público atendido por essa EMEI.

A investigação se deu por meio de técnicas de coleta de dados como a análise documental, entrevistas semiestruturadas e observação participante (LUDKE; ANDRÉ, 1986, SANTOS, 1999, 1996). Para a coleta de dados inicialmente foi realizada uma leitura minuciosa do Projeto Político Pedagógico (PPP) da Instituição, do projeto institucional (PI) para o ano de 2018 e do projeto da turma (PT), a fim de se analisar o currículo da EMEI, suas propostas e orientações para o trabalho relacionado à educação étnico-racial. Em seguida, foram realizadas duas entrevistas, com as professoras da turma selecionada. As entrevistas tiveram como pano de fundo o trabalho sobre as relações étnico-raciais e seu entrelaçamento com e pelas práticas curriculares, visando identificar o que é praticado na instituição, as estratégias de trabalho e a intervenção sobre a temática (planejamento das ações antes, durante e depois das visitas aos museus). As entrevistas foram realizadas individualmente, sendo registradas de forma 
escrita, gravadas em áudio e transcritas.

A técnica da observação participante foi realizada na sala de aula e nas visitas aos museus pertencentes ao Percurso Território Negro como locus, em função dos objetivos propostos. Foram realizadas duas visitas com a turma selecionada, uma no Espaço do Conhecimento/UFMG e a outra no Museu de Artes e Ofícios. A observação centrou-se na identificação e registro das narrativas elaboradas pelas crianças sobre as relações étnico-raciais. A técnica para análise e tratamento dos dados foi a Análise de Conteúdo (BARDIN, 1977) e suas características foram articuladas para o fim desejado. A análise na perspectiva temática atendeu a pesquisa, já que a investigação gira em torno das possibilidades de construção de narrativas de um grupo de crianças ao visitar museus com percursos que tratam sobre as relações étnico-raciais, e como estes se relacionam com seus conteúdos curriculares. A proposta foi discutir com as crianças, que são ativas e participativas, e entendidas como sujeitos que expressam o que pensam, tornando-as protagonistas no processo de construção do conhecimento.

\section{A Preparação das Visitas ao Percurso Território Negro: O Currículo em Ação}

Algumas observações sobre as relações presentes no currículo, documentos e práticas escolares em diálogo entre o repertório cultural das crianças, o trabalho consistente da EMEI e as visitas aos museus foram privilegiadas no contato com esse Percurso. A instituição escolhida para a realização desta pesquisa, vislumbra lançar luz à presença do negro no Brasil e no exterior, considerando a produção e disseminação de conhecimentos destes atores, como sugere a sociologia das ausências como discutidas por Santos (2004). Esta sociologia realça a necessidade de fazer emergir os sujeitos, conhecimentos e culturas invisibilizados no currículo, numa tentativa de transformar as ausências e invisibilidades em presenças, em conhecimentos sobre o negro e a educação 
étnico-racial no cotidiano escolar.

É nesse movimento de visibilizar o negro e desvelar o contexto das relações étnico-raciais que a EMEI pesquisada insere o Projeto "Brasil e África - um elo de saber", fazendo emergir os sujeitos negros, suas presenças e contribuições para a sociedade, por meio de histórias, brincadeiras, pesquisas, imagens, músicas, vídeos e as visitas aos museus pertencentes ao Percurso Território Negro.

Para este estudo, interessaram-nos as visitas nestes equipamentos culturais. Essas visitas foram analisadas articulando-se as ações, práticas e intervenções dos sujeitos antes, durante e depois, buscando compreender a inserção dessa atividade no projeto das professoras, para ajudar a entender como as relações étnico-raciais são tratadas pelo currículo da Educação Infantil na EMEI pesquisada.

A preparação para as visitas, ao se pensar os processos educativos na perspectiva do respeito, da valorização e do reconhecimento da diversidade, com foco nas culturas africanas e afro-brasileiras, requer a reflexão sobre modos de agir, de conceber o conhecimento, e a criação de estratégias que articulem a temática racial aos demais conteúdos.

Com este propósito, a instituição deixa explícita, em seus documentos, a busca por meio de estratégias pedagógicas e curriculares para implementar a Lei 10.639/03, valorizando a "diversidade como elementos positivos e enriquecedores ao processo educativo" (ROCHA, 2009, p. 26) desde a primeira infância. Para desenvolver o projeto "Brasil e África - um elo de saber", as professoras definiram a metodologia de trabalho de modo a articular as diversas linguagens, pela literatura, e envolver os familiares das crianças.

\footnotetext{
${ }^{4}$ Com a finalidade de possibilitar às crianças da Educação Infantil um conhecimento significativo, foi elaborado o Projeto 'Brasil e África - um elo de saber', que corresponde à necessidade educativa voltada para a formação de valores e posturas que contribuam para que as crianças valorizem seu pertencimento étnico-racial tornando-se parceiros da cultura antirracista, do fortalecimento da dignidade e da promoção da igualdade real de direitos (EMEIVL, 2018).
} 
Inicialmente, uma lista de livros foi enviada para a casa das crianças. Essa lista foi pensada pelas professoras após pesquisa sobre a temática, para elencar aqueles livros que poderiam ser utilizados nas atividades. A família pôde sugerir os livros que seriam emprestados. Uma sacola literária foi confeccionada com as crianças, como parte do processo pedagógico, para visibilizar o trabalho de pesquisa sobre a África por meio das silhuetas e cores utilizadas. Toda semana as crianças levavam um livro para que a família pudesse conhecer e lhes contar a história. No retorno à escola, as crianças, em roda, expunham suas impressões e registros realizados. Esta prática de leitura se consolidou como forma de articular os saberes construídos e compartilhados entre família e escola.

Para possibilitar o trabalho, alicerçados na educação das relações étnico-raciais, foram planejadas ações e estratégias no desenvolvimento do projeto, com a escolha, seleção e aquisição de materialidade. Para além da mediação com a literatura, outras formas de arte e linguagens foram utilizadas ampliando o repertório cultural das crianças.

O passo seguinte do projeto "Brasil e África - um elo de saber" tinha como perspectiva conhecer e vivenciar essas ações por meio do patrimônio cultural nas visitas a museus do Percurso Território Negro do Circuito de Museus de BH. Esta estratégia possibilitou a ampliação, reconhecimento, cuidado e valorização da representatividade, da presença positiva do negro na sociedade, principalmente na produção de saberes, para a valorização das questões étnico-raciais.

O Percurso Território Negro: Reflexões Possibilitadas no Tempo do Lazer e da Experiência Lúdica 
Educação Étnico-racial de Crianças Pequenas no "Percurso Territorio Negro"...

Andreza Mara da Fonseca e Vânia Noronha

O planejamento prévio das visitas permitiu sua realização por meio das vivências, atividades e práticas pedagógicas em que se materializam o currículo e que ocorreram durante o projeto, contextualizando, ampliando e construindo novos conhecimentos acerca da presença do negro. A descrição sobre as visitas aos museus se alinha com o sugerido por Moreira (1995, p. 257), segundo o qual "o conhecimento corporificado no currículo precisa estar mais atento às vozes e às narrativas de grupos até então excluídos de participar de sua produção e criação". Isso porque o projeto e as visitas têm como fio condutor a educação das relações étnico-raciais sobre os negros. Durante as visitas, a todo momento, as crianças faziam relações com o trabalho realizado na escola, perguntas, constatações, inferências, dentre outros.

A participação das crianças nesses equipamentos foi potente. No EC/UFMG, dentre as perguntas feitas por uma criança, uma chamou a atenção: Aqui não tem máscaras africanas? Ela mesma responde articulando a visita com seus conhecimentos: É que a gente fez lá na escola! O retorno dessa visita se configurou como momento de indagações, euforias e decepções. As falas das crianças revelavam o que mais lhes despertava curiosidades além de destacar práticas cotidianas que ocorrem na escola e também estiveram presentes no museu, como as músicas, a contação de histórias e a ludicidade ao tratar sobre elementos da África.

Já no MAO, o setor educativo utilizou de estratégias como o filme e a contação de história, além do passeio para a apreciação do acervo. Os relatos das crianças versavam sobre o trabalho e a presença do negro, escravizado ou não. Elas mostraram interesse pelos artefatos do acervo, por exemplo, as balanças e utensílios dos barbeiros. Uma delas perguntou: Eles inventavam xampus como o Chico Juba? A monitora do educativo não entendeu a pergunta e outra criança interviu: Essa é uma história que a professora tinha contado lá na escola. A monitora, então, deu vazão a fantasia da 
primeira criança e respondeu afirmativamente: Sim, eles inventavam xampu e outros cremes. Notadamente a criança havia feito uma relação com a história conhecida que trata sobre os cabelos dos negros e a valorização das raízes negras pela estética. Outra fala de aluna reforça: Nós estamos trabalhando com a história "Bruna e a galinha d'Angola”. Mas não foi só essa, ouvimos também Chico Juba, Meninas negras, do Baobá... há um tantão de história! Igual daquela princesa que o rapaz contou no museu.

Os questionamentos e intervenções de fato enriqueceram o diálogo e, consequentemente, o trabalho, contribuindo para repensar visões sobre a África e a presença do negro no Brasil e no mundo, por meio de ações curriculares articuladas. As quais se materializaram nas práticas pedagógicas, intencionalmente pensadas para refletir sobre as questões étnico-raciais e a presença positiva do negro na sociedade, trabalhando por meio da literatura as demandas da turma.

Após revelar ações, práticas e subsídios em que o trabalho foi desenvolvido com as crianças, as professoras, na sala de aula, reverberam as narrativas que sobressaíram no campo: a presença do negro no Brasil e no mundo e as relações presentes no currículo, documentos e práticas, reafirmando o trabalho consistente da EMEI. Um currículo alicerçado em conteúdos e práticas não hierarquizadas, a diversidade, os diferentes modos, de ser, viver e saber, de forma planejada e intencional, pode empoderar, dar visibilidade e o reconhecimento necessários à luta contra o racismo e a discriminação.

Os dados da pesquisa também apresentam a potência do diálogo educacional entre o espaço da escola e o do museu, além de mostrar como as crianças, ao percorrerem estes dois territórios de educação e de lazer, estabelecem relações de aprendizagem quanto às questões étnico-raciais. Desse modo, as crianças acionam a imaginação e seus conhecimentos para interpretar os artefatos nas visitas aos museus e 
dialogam sobre tais conhecimentos entre si e com os adultos que fazem a mediação das visitas (professores e monitores), buscam relações entre o aprendido e o apresentado, opinam sobre fatos históricos, prestam atenção nas imagens, histórias e outros artefatos.

As referências sobre negros(as) a que tiveram acesso tanto na EMEI quanto nos museus, potencializaram uma identidade positiva nas crianças negras e nas professoras (também negras), assim como possibilitou às crianças brancas o acesso a conhecimentos sobre a história e cultura afro-brasileira que contradizem a narrativa hegemônica.

\section{Considerações Finais}

Este estudo trouxe importantes reflexões sobre uma possível mudança paradigmática na qual a relação entre a educação e o lazer encontram interfaces que podem contribuir para a formação de um sujeito imaginante e não apenas racional. Nesse sentido, estabeleceu-se inicialmente um diálogo entre o lazer, a teoria da complexidade e a antropologia do imaginário. Para contribuir com a reflexão, apresentamos uma pesquisa sobre a educação étnico-racial possibilitada pela articulação entre uma proposta curricular para a Educação Infantil de uma escola de Belo Horizonte e o Circuito de Museus, por meio do Percurso Território Negro, como uma das muitas iniciativas que encontramos na educação brasileira.

Esta pesquisa analisou a proposta de trabalho para uma turma de 5 (cinco) anos de uma EMEI, com foco na educação das relações étnico-raciais, e como estas são tratadas pelo currículo da Educação Infantil antes, durante e depois das visitas ao Percurso Território Negro. O que se observou, neste estudo de caso, foi que as atividades proporcionaram caminhos para que as crianças percorressem locais de protagonismo e pertencimento, na EMEI e nos museus, que oportunizaram maior 
visibilidade às questões focais do trabalho proposto pela instituição e objeto desta investigação.

Quanto às questões problematizadas desta investigação, a primeira constatação foi a de que nesta escola existem estratégias curriculares mobilizadoras para a realização das visitas das crianças aos museus, seja impulsionada pelo gestor ou de iniciativa própria por parte dos professores. A positividade do trabalho da EMEI com a educação das relações étnico-raciais merece destaque, já que a escola possui um trabalho consistente desde os documentos até as práticas, com uma gestão comprometida com o trabalho dando o suporte às professoras e estimulando-as a agirem.

No trabalho de campo foram identificadas as estratégias adotadas pelas professoras, como, por exemplo, pesquisas, utilização de imagens e vídeos, rodas de conversas, contações de histórias, brincadeiras. Estas foram realizadas de diferentes formas em acordo com as propostas e orientações sugeridas pelas Proposições Curriculares Municipais e descritas no projeto da turma e no PPP da instituição. Essa coerência foi detectada ao analisarmos os documentos de orientação curricular utilizados pela instituição que, além de apontar a necessidade do trabalho com a educação das relações étnico-raciais trouxe, dentre outras ações, promoveu as visitas aos museus como parte integrante do trabalho com a cultura, valorizando a diversidade e o acesso ao patrimônio cultural, ao explorar equipamentos específicos de lazer na cidade. Ainda que não esteja explícito no PPP, cabe-nos acreditar que a escola reconhece o potencial educativo do lazer e sua multiplicidade de possibilidades quando explorados outros tempos e espaços para a imaginação e a aprendizagem.

Já sobre a relação étnico-racial, as narrativas que as crianças expressaram ao longo das visitas aos museus e a maneira como as narrativas foram tratadas pelo currículo escolar, refletiram o trabalho realizado antes das visitas na EMEI, ao fazerem 
inferências sobre histórias, imagens, vídeos, brincadeiras, atividades de registro ou pesquisas realizadas. As narrativas revelaram ainda que as crianças possuem repertório de história e cultura afro-brasileira, pois esses pequenos sujeitos dialogaram intensamente com a linguagem museal, interpretando artefatos culturais com os quais entraram em contato, além de dialogar entre si e com os adultos. As crianças buscaram também relações entre o repertório cultural que possuíam para compreender as informações disponibilizadas pelo espaço do museu, ou seja, entre o aprendido e o apresentado, realizando observações com base nas histórias que conheciam. Desse modo, refletiram sobre o ser negro(a), e sobre fatos históricos relacionados aos negros, além de interrogaram os espaços dos museus.

O protagonismo infantil e docente foi evidenciado na EMEI e nas visitas aos museus, já que as crianças disseram o que viram e também o que gostariam de ver, indicando um dos aportes da educação das relações étnico-raciais, que é a possibilidade de fazer circularem conhecimentos. Educar para as relações raciais é, portanto, interferir na constituição de referenciais, dos saberes que influenciam decisivamente na formação de personalidades, de visões de mundo e dos códigos comportamentais que orientam a forma como o indivíduo se percebe e se posiciona - como ele vê a sociedade e como aprende a transitar nela.

Por isso, foi destacada a importância da interlocução interdisciplinar entre lazer (por meio do museu) e escola, bem como as relações estabelecidas pelas crianças ao percorrerem o Percurso Território Negro e as aprendizagens possibilitadas. Destaca-se, ainda, como o espaço museal e seu acervo, ao buscarem olhar para o passado sob a ótica de referenciais positivos, contribuem para valorizar a presença do povo negro no Brasil e no mundo. 
Dessa forma, este trabalho contribui para a emergência de futuros estudos que considerem o potencial educacional da educação e linguagem museal no debate sobre as relações étnico-raciais, a valorização da diversidade e a constituição de outros imaginários. Essa pesquisa contribui para o desenvolvimento de uma possível Pedagogia do Imaginário, em que outras linguagens possam convergir para uma educação sensível de nossas crianças, com vistas a educá-las não só para as exigências do mercado, mas, também, para viver a ludicidade, a emoção, a fantasia, o sonho, a poesia, a arte e demais fenômenos que constituem a nossa formação humana imaginante.

Este trabalho contribui ainda para que os sujeitos da educação possam usufruir da cultura, como protagonistas e não apenas espectadores, reconhecendo os equipamentos de lazer das cidades, ocupando-os, exercitando o pertencimento aos mesmos, além de fomentar políticas públicas para a garantia do direito à essa importante dimensão da vida. E contribui, principalmente, para que nossas crianças possam, ao explorarem seus corpos lúdicos em diferentes situações, se reconhecer negros e negras, valorizar sua ancestralidade e cultura, resistir e lutar para reduzir ações racistas, preconceituosas, discriminatórias em nossa sociedade. Desse modo, permitir que negros(as) de nossa sociedade possam viver a potência de seus corpos, sua corpotência, como diria Bastos (2021), única, diversa, lúdica, imaginante, amorosa e sensível!

\section{REFERÊNCIAS}

ALMEIDA, S. L. de. O que é racismo estrutural? Belo Horizonte: Letramento, 2018.

BAStOS, J. Muito Prazer! Presença Afro, Belo Horizonte, Ano XVIII, n.45, janeiro a julho 2021.

BARDIN, L. Análise de conteúdo. Lisboa: Edições 70, 1977.

BRASIL. Ministério da Educação. Base Nacional Comum Curricular. Brasília, 2018. 
BRASIL. Lei n. 11.645, de 10 de março de 2008. Altera a Lei no 9.394, de 20 de dezembro de 1996, modificada pela Lei no 10.639, de 9 de janeiro de 2003, que estabelece as diretrizes e bases da educação nacional, para incluir no currículo oficial da rede de ensino a obrigatoriedade da temática "História e Cultura Afro-Brasileira e Indígena”. Diário Oficial da União, Brasília, 11 de março de 2008.

BRASIL. Lei n. 10.639, de 09 de janeiro de 2003. Inclui a obrigatoriedade da temática "História e Cultura Afro-brasileira" no currículo oficial da rede de ensino. Diário Oficial da União, Brasília, 9 de janeiro de 2003.

BRASIL. Referencial Curricular Nacional para a Educação Infantil. Ministério da Educação e do Desporto, Secretaria de Educação Fundamental. Brasília, MEC/SEF, 1998. In: Pedagogia ao Pé da Letra, 2013. Disponívelem: https://pedagogiaaopedaletra.com/rcnei-referencial-curricular-para-educacao-infantil/. Acesso em: 6 out. 2021.

BRASIL. Constituição (1988). Constituição da República Federativa do Brasil. 40. ed. São Paulo: Saraiva, 2007.

BRASIL. Lei n. 8.069, de 13 de julho de 1990. Dispõe sobre o Estatuto da Criança e do Adolescente, e dá outras providências. Diário Oficial da União, Brasília, 16 de julho 1990.

CANCLINI, N. G. Culturas híbridas: estratégias para entrar e sai da modernidade. São Paulo: EDUSP, 1997.

CANEVACCI, M. A cidade polifônica. Ensaios sobre a antropologia da comunicação urbana. São Paulo: Studio Nobel, 1993.

CASTRO-GÓMEZ, S. Ciências Sociais, violência epistêmica e o problema da "invenção do outro". In: LANDER, E. (Org.). A colonialidade do saber: eurocentrismo e ciências sociais. Perspectivas latino-americanas. Colección Sur Sur. CLACSO, Buenos Aires: Ciudad Autónoma de Buenos Aires, 2005. p. 87-95.

CORSARO, W. Sociologia da Infância. Porto Alegre: Artmed, 2011.

CURY, C. R. J. Direito à Educação: direito à igualdade, direito à diferença. Cadernos de Pesquisa, São Paulo, n. 116, p. 245-262, 2002.

CURY, C. R. J. Qualidade em Educação. Belo Horizonte, 2007.

DUBORGEL, B. Imaginário e pedagogia. In: ARAÚJO, A. F.; BAPTISTA, F. P. (Orgs). Variações sobre o imaginário. Domínios, teorizações, práticas hermenêuticas. Lisboa: Instituto Piaget, 1992. p. 203-217.

DURAND, G. As estruturas antropológicas do imaginário. 3 ed. São Paulo: Martins Fontes, 2002.

DUTRA, S. F. As crianças e o desenvolvimento da temporalidade histórica. 2003. Dissertação (Mestrado em Educação) - Faculdade de Educação, Universidade Federal de Minas Gerais, Belo Horizonte, 2003. 
ESCOLA MUNICIPAL DE EDUCAÇÃO INFANTIL VILA LEONINA (EMEIVL). Projeto de Turma EMEI - 'Brasil e África - um elo de saber', que corresponde a necessidade educativa voltada para a formação de valores e posturas que contribuam para que as crianças valorizem seu pertencimento étnico-racial tornando-se parceiros da cultura antirracista, do fortalecimento da dignidade e da promoção da igualdade real de direitos. Belo Horizonte: EMEIVL, 2018.

ESPAÇO DO CONHECIMENTO-UFMG. Belo Horizonte, MG, Brasil. Disponível em: http://www.espacodoconhecimento.org.br/. Acesso em: 22 jan. 2019.

FONSECA, A. M. da. “Aqui não tem máscaras africanas?” A educação étnico-racial em uma EMEI e a experiência com o percurso território negro em museus de Belo Horizonte/MG. 2019. 132 f. Dissertação (Mestrado) - Pontifícia Universidade Católica de Minas Gerais, Belo Horizonte, 2019.

FONSECA, A.; NORONHA, V. “Aqui não tem máscaras africanas?” A educação étnico-racial em uma EMEI e a experiência com o Percurso Território Negro em museus de Belo Horizonte/MG. In: CONGRESSO BRASILEIRO DE PESQUISADORE(AS) NEGROS(AS), COPENE, 11., 2020, Curitiba. Anais... Curitiba: Associação Brasileira de Pesquisadores(as) Negros(as), 2020. Disponível em: https://drive.google.com/drive/folders/1iQHs9gW45UBuAfmJYO4NKS608SelU1Ug. Acesso em: 09 nov. 2021.

GOMES, C. L.; ISAYAMA, H. F. O lazer e as fases da vida. In: MARCELLINO, N. C. (Org.). Lazer e sociedade. Múltiplas relações. Campinas: Editora alínea, 2008.

GOMES, C. L. Lazer e produção do conhecimento. Belo Horizonte/Rio de Janeiro: UFMG/SESC-DN, 2019.

GOMES, N. L. Movimento negro e educação: ressignificando e politizando a raça. Educação \& Sociedade [online]. v. 33, n. 120, p. 727-744, 2012, Disponível em: https://doi.org/10.1590/S0101-73302012000300005. Acesso em 15 dez. 2021. Epub 24 Out 2012. ISSN 1678-4626. https://doi.org/10.1590/S0101-73302012000300005.

GOMES, N. L. O movimento negro educador. Saberes construídos na luta por emancipação. Petrópolis: Vozes, 2017.

KRENAK, A. Ideias para adiar o fim do mundo. São Paulo: Companhia das Letras, 2019.

LÜDKE, M.; ANDRÉ, M. E. D.A. Pesquisa em educação: abordagens qualitativas. São Paulo: EPU, 1986.

MOREIRA, A. F. B. O currículo como política cultural e a formação docente. In: SILVA, T. T.; MOREIRA, A. F. B. (Org.). Territórios contestados: o currículo e os novos mapas políticos e culturais. Petrópolis: Vozes, 1995. p. 7-20.

MORIN, E. Recordar: Edgar Morin no Roda Viva em 2000a. Programa Roda Viva. Disponível em: https://emorin.com.br/recordar-edgar-morin-no-roda-vida-em-2000/\#. Acesso em: 04 out. 2021.

MORIN, E. Ciência com Consciência. 5. ed. Rio de Janeiro: Bertrand Brasil, 2000b. 
MUSEU DE ARTES E OFÍCIOS. Belo Horizonte, MG, Brasil. Disponível em: https://www.mao.org.br/sobre/. Acesso em: 24 jul. 2021.

NORONHA, V. Rastros de África no Brasil: práticas educativas no Reinado de Nossa Senhora do Rosário. Belo Horizonte: Mazza Edições, 2017.

PAULA CARVALHO, J. C. Antropologia das organizações e educação. Um ensaio holomônico. Rio de Janeiro: Imago Editora, 1990.

PELEGRINI, A. de. Equipamentos de Lazer. In: GOMES, C. L. (Org.). Dicionário Crítico de Lazer Belo Horizonte: Autêntica, 2004. p. 69-73.

QUINTEIRO, J. Sobre a emergência de uma sociologia da infância: contribuições para o debate. Revista Perspectiva, Florianópolis, v. 20, p. 137-162, 2002.

REIS, M. Notas sobre a Sociologia da Infância. In: CONGRESSO DA SOCIEDADE BRASILEIRA DE SOCIOLOGIA, 14., 2009, Rio de Janeiro. Anais... Porto Alegre: SBS, $2009 . \quad$ p. $1-11 . \quad$ Disponível em:http://www.anped.org.br/gruposdetrabalho/gt14sociologiadaeduca\%C3\%A7\%C3\% A3o. Acesso em: 16 jul. 2017.

ROCHA, R. M. C. Pedagogia da diferença: a tradição oral africana como subsídio para a prática pedagógica brasileira. Belo Horizonte: Nandyala, 2009.

RUIZ, C. M. M. B. Os paradoxos do imaginário. Sinos: Editora Unisinos, 2003.

SANTOS, B. S. (Org.). Conhecimento prudente para uma vida decente. São Paulo: Cortez, 2004.

SANTOS, B. S. "Para uma Pedagogia do Conflito". In: SILVA, L. H. da et al. (Orgs.). Novos Mapas Culturais, Novas Perspectivas Educacionais. Porto Alegre: Editora Sulina,1996. p. 15-33.

SANTOS, B. S. Reinventar a democracia: entre o pré-contratualismo e o póscontratualismo, in Oliveira, Francisco de e Paoli, Maria Célia (org.). Os sentidos da democracia - Políticas do dissenso e hegemonia global. São Paulo: Editora Vozes, FAPESP e NEDIC, 1999. 83-129.

SANTOS, B. S. Direito e democracia. A reforma global da justiça. In: PUREZA, J. M.; FERREIRA, A. C. (Orgs.). A teia global: movimentos sociais e instituições. Porto: Edições Afrontamento, 2002. p. 125-176.

SANTOS, R. E. dos. Refletindo sobre a Lei 10.639: possibilidades e necessidades do ensino de geografia a partir de um tensionamento do Movimento Negro. In: ENCONTRO DE GEÓGRAFOS DA AMÉRICA LATINA-EGAL, 12., 2009, Montevidéo. Anais... Quito: AGEc, 2009. p. 1-15.

SAURA, S. C. O imaginário do lazer e do lúdico anunciado em práticas espontâneas do corpo brincante. Revista Brasileira de Educação Física e Esporte, São Paulo, v. 28, n. 1, p. 163-75, 2014. 1 Disponível em https://www.scielo.br/j/rbefe/a/KT3JS89J3dKdcB5wrmsrj7f/?lang=pt\&format=pdf. Acesso em: 05 out. 2021. 
SARMENTO, M. J. Gerações e alteridade: interrogações a partir da Sociologia da Infância. Revisa Educação e Sociedade, Campinas, v. 26, n. 91, p. 361-378, 2005.

SILVEIRA, G. C. F. da. Entre celulares, tablets, consoles e computadores: práticas digitais de adolescentes de uma escola pública de ensino fundamental. 2019. $249 \mathrm{f}$. Tese (Doutorado em Estudos do Lazer) - Escola de Educação Física, Fisioterapia e Terapia Ocupacional, Universidade Federal de Minas Gerais. Belo Horizonte. 2019.

SODRÉ, M. Reinventando a educação: diversidade, descolonização e redes. Petrópolis: Vozes, 2012.

VAZ, A. F. Reflexões de passagem sobre o lazer: notas sobre a pedagogia da indústria cultural. Revista Pensar a Prática, Belo Horizonte, v. 1, n. 9, p. 13-26, jan./jun. 2006. Disponível em https://www.revistas.ufg.br/fef/article/view/122. Acesso em: 20 set. 2021.

\section{Endereço das Autoras:}

Andreza Mara da Fonseca

Endereço Eletrônico: a.m.r.oliveira@edu.pbh.gov.br

Vânia Noronha

Endereço Eletrônico: vfna@icloud.com 